\title{
Pro: Can neuropathology really confirm the exact diagnosis?
}

\author{
Margaret M Esiri*
}

\begin{abstract}
Recent advances in the clinical diagnostic instruments for diagnosing Alzheimer's disease (AD) and in neuroimaging may cast doubt in the minds of some practitioners about the continued need for neuropathology to provide the ultimate diagnosis. Certainly the majority of cases of AD can be clinically correctly diagnosed by experienced clinicians but many cases are given this label by less experienced practitioners. Even after the most thorough work-up, a few cases of confidently diagnosed AD turn out to be something else when microscopy of the brain is undertaken. Even for neuropathologists, however, it can be difficult to correctly assign cognitive decline to the various pathological processes that can be found together in an older brain. We need further clinicopathogical study to enlighten us about, for example, the contribution of commonly found cerebrovascular disease to dementia. Human studies are also needed to explore the changes in pathology that new treatments for AD may produce.
\end{abstract}

There was a time (up to the 1960s and 1970s) when few would have questioned that a neuropathological examination of the brain at autopsy was needed to make a diagnosis of Alzheimer's disease (AD). This was at a time when clinical diagnostic instruments and neuroimaging were in their infancy. It was also a time when dementia was clinically divided into pre-senile and senile forms and the $\mathrm{AD}$ pathological label was applied most confidently in pre-senile cases. Much has changed since then, and it is appropriate to ask whether neuropathology is still the gold standard by which to reach such a diagnosis.

Many cases of clinical AD are correctly diagnosed in life if the person concerned is seen by a specialist with much experience of the condition. The proportion of cases

*Correspondence: Margaret.Esiri@cIneuro.ox.ac.uk

Neuropathology Dept, West Wing, John Radcliffe Hospital, Oxford OX3 9DU, UK correctly diagnosed will continue to climb if specialists have access to advancing imaging and other diagnostic procedures. The situation is different, however, if the diagnosis is made by someone without specialised knowledge or without access to state-of-the-art investigations.

Even among cases seen by specialists there will be a few that defy a correct diagnosis either because they present atypically or because a rare disease is masquerading as clinical AD. I have seen both. Frontotemporal dementia and $\mathrm{AD}$ can sometimes be indistinguishable until microscopic sections have been examined. These cases cannot be correctly diagnosed without recourse to the microscope, and even then may fail to fit criteria for a diagnostic label. Only through the careful pathological assessment of such cases, however, often assisted by new pathological techniques (for example, new antibodies, genetic probes), will progress in delineating new or newly recognised diseases evolve.

Although it may at present only be in the minority of cases that neuropathology is required to attach the correct diagnosis to a case of dementia, it can be difficult to predict in life which cases will fall into this category. Furthermore, diseases change and evolve over time. One hundred years ago it was possible to clinically confuse AD with tertiary syphilis but pathology provided a ready distinction. Now it is more likely that confusion might arise with respect to $\mathrm{AD}$ and AIDS-related dementia. Where will the confusion come from in the future? We need to remain watchful for novel forms of disease arising, and we need look no further than new variant Creutzfeldt-Jakob disease to be reminded of this.

Affixing a single, specific diagnostic label, whether at the clinical or pathological level, is generally more easily achieved in young patients in whom the brain succumbs to a single pathological process. The difficulty with $\mathrm{AD}$ is that it is a condition whose incidence rises exponentially with age [1] when multiple factors may contribute to cognitive decline. These are likely to be different in different individuals and not all of them can yet be apportioned their real share of blame. Hence, unitary diagnoses are much less likely to apply. It was through pathological studies that we were made aware of how much cerebrovascular disease, particularly small vessel 
subcortical disease, and AD pathology co-exist [2]. True, vascular disease can now be assessed quite well with neuroimaging, but we still lack thorough understanding of exactly what contribution cerebrovascular disease makes to cognitive impairment [3].

We still need well-designed clinicopathological studies to acquire a much better understanding of the complexities of the pathological basis of cognitive decline in the older person and the many factors that feed into the clinical expression of pathological disease. Pathological examination of the brain provides a much more secure foundation on which to base understanding of the cellular and molecular changes that contribute to dementia, including $\mathrm{AD}$, than do clinical and imaging data. Community-based studies have shown us how misleading can be the impression of rather stereotyped disease that is gained from case-control cohorts. Unbiased (blind to cognitive function) pathological assessment of brains from a random community sample of older subjects such as is provided in the UK by the Medical Research Council Cognitive Function and Ageing Study (www.cfas. ac.uk) - enable us to appreciate how variable is clinical expression of AD pathology [4-6]. Such studies indicate the need to uncover the factors that enable someone with well-developed pathological features of $\mathrm{AD}$ to perform perfectly well in activities of daily life. Such knowledge will be essential given the massive rise in the world's older population.

Until we have reliable biomarkers that enable a confident diagnosis of $\mathrm{AD}$ to be made in life, which reflects the pathological basis of this disease, an autopsy examination of the brain remains an essential tool. With all due respect I would venture to say that we delude ourselves if we think we can reach a molecular understanding of this still enigmatic disease without an opportunity to explore cellular and molecular changes in affected human brains. Furthermore, it is essential to study at autopsy the brains of people who have participated in clinical trials, since this is the way to gain clarity over whether the treatment manages to abolish the pathology. Examination of a meagre eight cases treated with the initial anti- $\beta$-amyloid vaccine showed clearly that, while the amyloid plaques were reduced in most of the cases, the neurofibrillary tangles remained in place [7]. Tangles, as has long been known, are the pathological feature that best correlates with how demented is a patient with $\mathrm{AD}[8,9]$.

Looking to the future, there may be less need to have recourse to the practised eye of neuropathologists experienced in diagnosing causes of dementia. Use of western blotting on fresh-frozen brain homogenates offers another way to examine pathological brain changes, although this method is not yet in routine use for this purpose except in the case of prion diseases [10]. I accept that there may come a time when conventional neuropathology no longer has a part to play in helping to diagnose and understand $\mathrm{AD}$, but that time has not yet come and, in my opinion, is likely to be a good way off. Autopsy examination of well-studied cases of AD and other dementias still has a critical role to play.

\section{Abbreviations}

$\mathrm{AD}$, Alzheimer's disease.

\section{Competing interests}

The author declares that she has no competing interests.

\section{Published: 7 May 2010}

\section{References}

1. Ott A, Breteler MM, van Harskamp F, Claus JJ, van der Cammen TJ, Grobbee DE, Hofman A: Prevalence of Alzheimer's disease and vascular dementia: association with education. The Rotterdam study. BMJ 1995, 310:970-973.

2. Morris JH, Kalimo H, Viitanen M: Vascular dementias. In The Neuropathology of Dementia. 2nd edition. Edited by Esiri MM, Lee VM-Y, Trojanowski JQ. Cambridge University Press; 2004:289-329.

3. Jellinger KA: Morphologic diagnosis of 'vascular dementia' - a critical update. J Neurol Sci 2008, 270:1-12.

4. Neuropathology Group. Medical Research Council Cognitive Function and Aging Study: Pathological correlates of late-onset dementia in a multicentre, community-based population in England and Wales. Neuropathology Group of the Medical Research Council Cognitive Function and Ageing Study (MRC CFAS). Lancet 2001, 357:169-175.

5. Savva GM, Wharton SB, Ince PG, Forster G, Matthews FE, Brayne C: Age, neuropathology and dementia. N Engl J Med 2009, 360:2302-2309.

6. Ewbank DC, Arnold SE: Cool with plaques and tangles. N Engl J Med 2009, 360:2357-2358.

7. Holmes C, Boche D, Wilkinson D, Yadegarfar G, Hopkins V, Bayer A, Jones RW, Bullock R, Love S, Neal JW, Zotova E, Nicoll JA: Long term effects of A $\beta 42$ immunisation in Alzheimer's disease: follow-up of random placebocontrolled phase 1 trial. Lancet 2008, 372:216-223.

8. Wilcock GK, Esiri MM: Plaques, tangles and dementia: a quantitative study. J Neurol Sci 1982, 56:343-356.

9. Nagy Z, Esiri MM, Jobst KA, Morris JH, King EM, McDonald B, Litchfield S, Smith A, Barnetson L, Smith AD: Relative roles of plaques and tangles in the dementia of Alzheimer's disease: correlations using three sets of neuropathological criteria. Dementia 1995, 6:21-31

10. Ironside JW, Ghetti B, Head MW, Piccardo P, Will RG: Prion diseases. In Greenfield's Neuropathology. Volume 2.8th edition. Edited by Love S, Louis DN, Ellison DW. London: Hodder Arnold; 2008:1197-1273.

doi:10.1186/alzrt33

Cite this article as: Esiri MM: Pro: Can neuropathology really confirm the exact diagnosis? Alzheimer's Research \& Therapy 2010, 2:10. 